\title{
Upgrade rates of high-risk breast lesions diagnosed on core needle biopsy: a single- institution experience and literature review
}

\author{
Kelly L Mooney ${ }^{1}$, Lawrence W Bassett ${ }^{2}$ and Sophia K Apple ${ }^{3}$ \\ ${ }^{1}$ David Geffen School of Medicine at UCLA, Los Angeles, CA, USA; ${ }^{2}$ Department of Radiology, David Geffen \\ School of Medicine at UCLA, Los Angeles, CA, USA and ${ }^{3}$ Department of Pathology \& Laboratory Medicine, \\ David Geffen School of Medicine at UCLA, Los Angeles, CA, USA
}

\begin{abstract}
Optimal management of high-risk breast lesions detected by mammogram yielding atypical ductal hyperplasia, flat epithelial atypia, atypical lobular hyperplasia, lobular carcinoma in situ, and radial scar without atypia on core needle biopsy is controversial. This is a single-institution retrospective review of $\mathbf{5 7 5 0}$ core needle biopsy cases seen over 14.5 years, including $249(4.3 \%), 72(1.3 \%), 50(0.9 \%), 37(0.6 \%)$, and $54(0.9 \%)$ cases of atypical ductal hyperplasia, flat epithelial atypia, atypical lobular hyperplasia, lobular carcinoma in situ, and radial scar without atypia, respectively. Patient age, radiologic characteristics, needle gauge, and excision diagnoses were recorded. Of 462 high-risk cases analyzed, $333(72 \%)$ underwent excision. Upgrade rate to ductal carcinoma in situ, pleomorphic carcinoma in situ, or invasive mammary carcinoma was $18 \%$ for atypical ductal hyperplasia, $11 \%$ for flat epithelial atypia, $9 \%$ for atypical lobular hyperplasia, $28 \%$ for lobular carcinoma in situ, and $16 \%$ for radial scar. Carcinoma diagnosed on excision was more likely to be in situ than invasive, and if invasive, more likely to be low grade than high grade. Overall, cases that were benign (vs high risk or carcinoma) on excision were less likely to have residual calcifications after biopsy $(17 \%$ vs $27 \%, P=0.013)$, and more likely to have a smaller mass size $(<1 \mathrm{~cm})(82 \%$ vs $50 \%, P=0.001)$. On subgroup analysis, atypical ductal hyperplasia cases that were benign (vs high risk or carcinoma) on excision were more likely to have smaller mass size $(<1 \mathrm{~cm})$ $(P=0.025)$. Lobular neoplasia diagnosed incidentally (vs targeted) on core needle biopsy was less likely to upgrade on excision (5\% vs $39 \%, P=0.002)$. A comprehensive literature review was performed, identifying 116 studies reporting high-risk lesion upgrade rates, and our upgrade rates were similar to those of more recent larger studies. Careful radiological-pathological correlation is needed to identify high-risk lesion subgroups that may not need excision.
\end{abstract}

Modern Pathology (2016) 29, 1471-1484; doi:10.1038/modpathol.2016.127; published online 19 August 2016

To excise or not to excise is the question posed when certain non-malignant but high-risk breast lesions are diagnosed on core needle biopsy after imaging detection. The appropriate post-core needle biopsy management of these lesions causes debate, with a variety of practices including surgical excision, close-clinical follow-up with short-term repeated imaging and possible consideration for riskreducing medication. Currently, high-risk lesions are diagnosed in fewer than $9 \%$ of core needle

Correspondence: Professor SK Apple, MD, Department of Pathology \& Laboratory Medicine, David Geffen School of Medicine at UCLA, UCLA Center for the Health Sciences, 10833 Le Conte Avenue, Los Angeles, CA 90095, USA.

E-mail: sapple@mednet.ucla.edu

Received 28 February 2016; revised 31 May 2016; accepted 2 June 2016; published online 19 August 2016 biopsy cases, but volumes will likely increase as advances in breast imaging techniques increase lesion detection. ${ }^{1-4}$

Core needle biopsy diagnoses such as atypical ductal hyperplasia, flat epithelial atypia, atypical lobular hyperplasia, lobular carcinoma in situ, and radial scar are some the non-malignant lesions that are considered high risk for carcinoma. Patients with radial scar and atypical ductal hyperplasia were found to have a two-fold and up to five-fold increased risk of breast cancer over the general population, respectively. ${ }^{5-7}$ Increased risk of ipsilateral breast cancer was seen in patients with atypical lobular hyperplasia and lobular carcinoma in situ. ${ }^{8}$ And histologic and genetic similarities have been described between flat epithelial atypia and carcinoma. $^{9-11}$ 
Notably, these high-risk lesions are not only markers of future carcinoma, but also indicators of concurrent carcinoma missed due to biopsy sampling. Upgrade rates to ductal carcinoma in situ or invasive carcinoma from core needle biopsy to excision in the literature range from 0 to $62 \%$ for atypical ductal hyperplasia, 0 to $21 \%$ for flat epithelial atypia, 0 to $67 \%$ for atypical lobular hyperplasia, 0 to $60 \%$ for lobular carcinoma in situ, and 0 to $16 \%$ for radial scar. ${ }^{12-21}$ Given these data, it is not surprising that the management of high-risk breast lesions seen on core needle biopsy is controversial. More defined upgrade rate data are needed and may prevent over- and undertreatment.

The present study evaluates excision results for patients with non-malignant high-risk lesions, including atypical ductal hyperplasia, flat epithelial atypia, atypical lobular hyperplasia, lobular carcinoma in situ, and radial scar without atypia diagnosed on core needle biopsy at our institution. Additionally, we investigate the predictive role of clinicopathological features including patient age, Breast Imaging Reporting and Data System (BIRADS) score, calcification span, mass size, and needle gauge on management and excision diagnosis. This is one of the largest studies elaborating on variables that predict benign diagnosis on excision, in addition to establishing baseline upgrade rates. We subsequently present the most comprehensive literature review to date, and conclude with a summary of our statistically significant findings with recommendations, providing a reference for the management of high-risk breast lesions diagnosed on core needle biopsy.

\section{Materials and methods}

After obtaining IRB approval, our pathology database was searched using the terms atypical ductal hyperplasia, flat epithelial atypia, atypical lobular hyperplasia, lobular carcinoma in situ, and radial scar on breast core needle biopsy cases from 1 January 2003 to 30 June 2014. Both imagingtargeted lesions and incidental pathologic findings were included. Radiologists at our institution used smaller 11- to 14-gauge needles from 2003 through 2005, and then larger 9-gauge needles were introduced and used almost consistently after 2007. Over the duration of the study, four subspecialized breast pathologists classified cases. Original slides were not re-reviewed for the purposes of this study. However, per institutional quality assurance policy, every breast core needle biopsy case was reviewed by a second pathologist within 1 week of original sign out. In addition, diagnoses were confirmed by a second pathologist during tumor board for excisional biopsy cases upgraded to ductal carcinoma in situ and/or invasive carcinoma.

For analysis, cases were assigned to appropriate high-risk entity categories (Figure 1). We excluded atypical ductal hyperplasia bordering on ductal carcinoma in situ, pleomorphic lobular carcinoma in situ, other variants of lobular carcinoma in situ such as florid/distended lobular carcinoma in situ with central necrosis, and radial scar associated with any type of epithelial atypia. Core needle biopsy cases with juxtaposed known synchronous ipsilateral breast carcinoma were also excluded. For flat epithelial atypia, cases from 2003 diagnosed using historical names such as 'columnar cell change with atypia', 'columnar cell hyperplasia with atypia', or 'columnar alteration with prominent apical snouts and secretions' were included. Only pure flat epithelial atypia cases were included in the flat epithelial atypia category for this study. If flat epithelial atypia was seen with lobular neoplasia, we tabulated the case under either atypical lobular hyperplasia or lobular carcinoma in situ. If flat epithelial atypia was seen with atypical ductal hyperplasia, then we tabulated the case under atypical ductal hyperplasia. Cases with focal and incidental lobular neoplasia seen with atypical ductal hyperplasia were included in the atypical ductal hyperplasia analysis. Other mixed atypical lesions were excluded.

From the electronic medical record, clinical and radiologic data for core needle biopsy cases were recorded, including patient age, Breast Imaging Reporting and Data System (BI-RADS) score, imaging findings (ie mass or calcification), calcification span, mass size, whether or not residual calcifications were noted after core needle biopsy, and needle gauge. Only cases with radiographic findings were included in this study. During the 14.5 year duration of the study, all cases were reviewed during weekly radiology-pathology concordance conferences. Electronic record review of radiology-pathology concordance comments revealed $<1 \%$ (3 of 462) cases were disconcordant. All three cases with histologic findings not explained by imaging findings were diagnosed as radial scar on biopsy, and two of the three cases went to excision while the third was lost to follow-up.

Our current institution guidelines include recommendation for excision in the setting of atypical ductal hyperplasia, lobular carcinoma in situ, atypical lobular hyperplasia, flat epithelial atypia, and radial scar. More recently, recommendations for excision or surveillance were made on a case-bycase basis after radiology-pathology correlation conference and with patient input.

For the analysis, upgrades were defined as ductal carcinoma in situ, pleomorphic lobular carcinoma in situ, and invasive mammary carcinoma on excision. Residual high-risk lesions such as atypical ductal hyperplasia, lobular carcinoma in situ, atypical lobular hyperplasia, and flat epithelial atypia on excision were not included as upgrades.

For categorical variables, statistical comparisons between groups were made using $\chi^{2}$ or Fisher's exact test, where appropriate. For normally distributed 

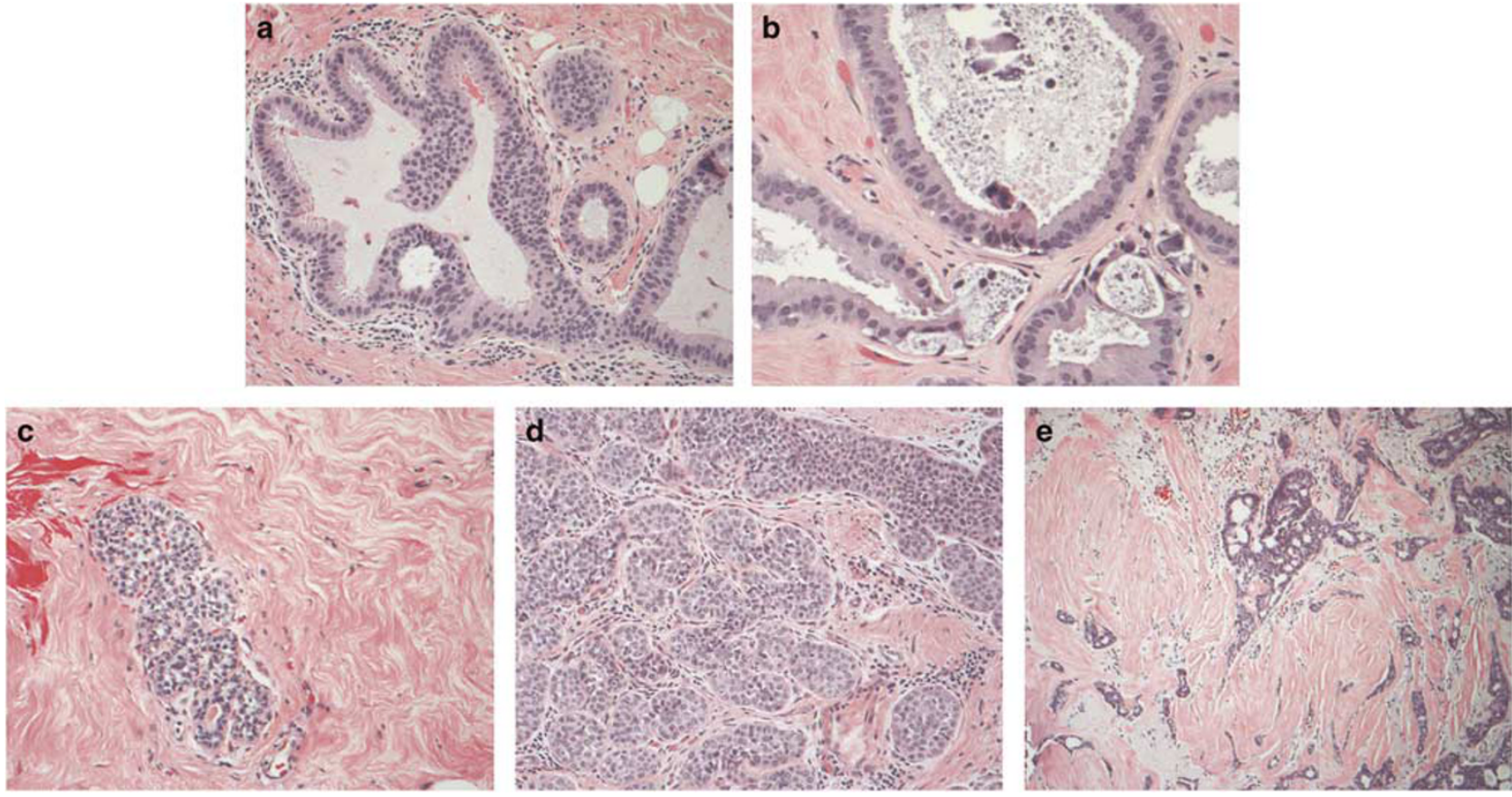

Figure 1 High-risk breast lesions. (a) Atypical ductal hyperplasia with low-grade nuclear atypia demonstrating 'roman bridge' and micropapillary architectural complexities. (b) Flat epithelial atypia, often detected due to luminal microcalcifications, consists of a monolayer of cytologically low-grade columnar-shaped cells with luminal 'tomb-stone' snouts lining a distended duct. (c) Atypical lobular hyperplasia consisting of uniform, dishesive small cells. (d) Lobular carcinoma in situ with small dishesive cells filling and expanding ductules. (e) Radial scar is a stellate lesion with a central elastic stroma and ducts radiating out, entrapped in a background of fibroelastosis, often mimicking a low-grade invasive ductal carcinoma, as seen on this core needle biopsy. (a, c, e: hematoxylin and eosin $\times 20 ; \mathbf{b}, \mathbf{d}$ : hematoxylin and eosin $\times 40$ )

continuous variables, comparisons were made using $t$-test. Multivariate analysis was conducted using stepwise logistic regression. All tests of significance were two-tailed, and significance was set at $P<0.05$. Statistical analysis was performed with SPSS statistical software (Statistical Package for the Social Sciences, IBM Corp., Version 22.0, Armonk, NY, USA).

\section{Results}

Over 14.5 years, 5750 core needle biopsy cases were collected, including 2589 stereotactic, 2913 ultrasound-guided, and 248 MRI-guided biopsies. A total of $462(8 \%)$ high-risk breast lesion core needle biopsy cases were identified, including 249 (4.3\%) atypical ductal hyperplasia, $72(1.3 \%)$ flat epithelial atypia, $50(0.9 \%)$ atypical lobular hyperplasia, 37 $(0.6 \%)$ lobular carcinoma in situ, and $54(0.9 \%)$ radial scar. The average patient age in years at index diagnosis was 55.0 for atypical ductal hyperplasia, 52.2 for flat epithelial atypia, 52.6 for atypical lobular hyperplasia, 54.2 for lobular carcinoma in situ, and 53.2 for radial scar.

Excision results were available for 333 cases, including $78,77,76,64$, and $46 \%$ of lobular carcinoma in situ, atypical ductal hyperplasia, flat epithelial atypia, atypical lobular hyperplasia and radial scar cases, respectively (Table 1 ). No excision results were available for 129 cases, including 22, 23, 24,36 , and $54 \%$ of lobular carcinoma in situ, atypical ductal hyperplasia, flat epithelial atypia, atypical lobular hyperplasia, and radial scar cases, respectively. Of 129 cases that did not undergo excision, 67 (52\%) were lost to follow-up, while 62 $(48 \%)$ were not excised for other reasons. Many cases lost to follow-up either had no further documentation in the medical record after the biopsy of interest, or had subsequent major illness diagnosed or emergency department visit documented. Cases with no excision that were not lost to followup had imaging follow-up at 6 months or later describing no progression of the targeted lesion of concern. Nine of $62(15 \%)$ of no excision cases had surgeon documentation of patient decision to not proceed with excision.

Follow-up results were further analyzed by entity. Of 57 atypical ductal hyperplasia cases that were not excised, $34(61 \%)$ were lost to follow-up, while 23 $(40 \%)$ were not excised, including 14 cases with imaging follow-up, 7 cases not excised due to patient input, and 2 cases treated with risk-reducing medication. Of 17 flat epithelial atypia cases that were not excised, 8 (47\%) were lost to follow-up, while 9 $(53 \%)$ were not excised including 8 cases with imaging follow-up and 1 case not excised due to patient input. Of 18 atypical lobular hyperplasia 
Table 1 Management and excision outcomes of high-risk lesions diagnosed on CNB

\begin{tabular}{|c|c|c|c|c|c|c|c|c|}
\hline \multirow{3}{*}{$\begin{array}{l}C N B \\
\mathrm{ADH} \\
(n=249)\end{array}$} & \multirow{3}{*}{$\begin{array}{c}\begin{array}{c}\text { Incidence } \\
(\mathrm{n}=5750)\end{array} \\
4.3 \%\end{array}$} & \multirow{3}{*}{$\begin{array}{l}\text { No excision } \\
57 / 249(23 \%)\end{array}$} & \multirow{3}{*}{$\begin{array}{c}\text { Excision } \\
192 / 249(77 \%)\end{array}$} & \multicolumn{5}{|c|}{ Excision findings } \\
\hline & & & & \multirow{2}{*}{$\begin{array}{l}\text { Benign } \\
51 / 192(26 \%)\end{array}$} & \multicolumn{2}{|c|}{ High risk } & \multicolumn{2}{|c|}{ Upgrade } \\
\hline & & & & & $106 / 192(55 \%)$ & $\begin{array}{l}84 \mathrm{ADH} \\
13 \mathrm{LN} \\
8 \mathrm{FEA} \\
1 \mathrm{RS}\end{array}$ & $35 / 192(18 \%)$ & $\begin{array}{l}29 \text { DCIS } \\
6 \text { IDC }\end{array}$ \\
\hline FEA $(n=72)$ & $1.3 \%$ & $17 / 72(24 \%)$ & $55 / 72(76 \%)$ & $20 / 55(36 \%)$ & $29 / 55(53 \%)$ & $\begin{array}{l}18 \mathrm{FEA} \\
11 \mathrm{ADH}\end{array}$ & $6 / 55(11 \%)$ & $\begin{array}{l}3 \text { DCIS } \\
2 \text { IDC } \\
1 \text { ITC }\end{array}$ \\
\hline ALH $(n=50)$ & $0.9 \%$ & $18 / 50(36 \%)$ & $32 / 50(64 \%)$ & $7 / 32(22 \%)$ & $22 / 32(69 \%)$ & $\begin{array}{l}10 \mathrm{ALH} \\
7 \mathrm{LCIS} \\
3 \mathrm{ADH} \\
2 \mathrm{FEA}\end{array}$ & $3 / 32(9 \%)$ & $\begin{array}{l}2 \text { DCIS } \\
1 \text { ILC }\end{array}$ \\
\hline LCIS $(n=37)$ & $0.6 \%$ & $8 / 37(22 \%)$ & $29 / 37(78 \%)$ & $4 / 29(14 \%)$ & $17 / 29(59 \%)$ & $\begin{array}{l}11 \mathrm{LCIS} \\
4 \mathrm{ADH} \\
2 \mathrm{ALH}\end{array}$ & $8 / 29(28 \%)$ & $\begin{array}{l}5 \text { DCIS } \\
1 \text { ILC } \\
1 \text { IDC } \\
1 \text { PLCIS }\end{array}$ \\
\hline RS $(n=54)$ & $0.9 \%$ & $29 / 54(54 \%)$ & $25 / 54(46 \%)$ & $16 / 25(64 \%)$ & $5 / 25(20 \%)$ & $\begin{array}{l}2 \mathrm{ADH} \\
2 \mathrm{ALH} \\
1 \mathrm{RS}\end{array}$ & $4 / 25(16 \%)$ & $\begin{array}{l}3 \text { DCIS } \\
1 \text { ILC }\end{array}$ \\
\hline $\begin{array}{l}\text { Cumulative } \\
(n=462)\end{array}$ & $8.0 \%$ & $129 / 462(28 \%)$ & $333 / 462(72 \%)$ & 98/333 (29\%) & $179 / 333(54 \%)$ & $\begin{array}{l}104 \mathrm{ADH} \\
45 \mathrm{LN} \\
28 \mathrm{FEA} \\
2 \mathrm{RS}\end{array}$ & $56 / 333(17 \%)$ & $\begin{array}{l}42 \text { DCIS } \\
9 \text { IDC } \\
3 \text { ILC } \\
1 \text { PLCIS } \\
1 \text { ITC }\end{array}$ \\
\hline
\end{tabular}

Abbreviations: ADH, atypical ductal hyperplasia; ALH, atypical ductal hyperplasia; CNB, core needle biopsy; DCIS, ductal carcinoma in situ; FEA, flat epithelial atypia; IDC, invasive ductal carcinoma; ILC, invasive lobular carcinoma; ITC, isolated tumor cells; LCIS, lobular carcinoma in situ; LN, lobular neoplasia; PLCIS, pleomorphic lobular carcinoma in situ; RS, radial scar.

Table 2 Characteristics of invasive tumors seen on excision of high-risk lesions diagnosed on CNB

\begin{tabular}{lccccccr}
\hline CNB & Excision & Grade & ER & PR & $\begin{array}{c}\text { HER2 } \\
\text { IHC }\end{array}$ & $\begin{array}{c}\text { HER2 } \\
\text { FISH }\end{array}$ & $\begin{array}{r}\text { Ki67 } \\
(\%)\end{array}$ \\
\hline ADH & IDC & 2 & + & + & - & - & 10 \\
ADH & IDC & 2 & + & + & - & - & 25 \\
ADH & IDC & 2 & + & + & - & - & 20 \\
ADH & IDC & 2 & + & + & - & - & 20 \\
ADH & IDC & 2 & + & + & - & - & 5 \\
ADH & IDC & 2 & + & + & - & - & 10 \\
FEA & IDC & 2 & + & + & - & - & 5 \\
FEA & IDC & 1 & + & - & - & - & $<5$ \\
LCIS & IDC & 3 & - & - & + & + & 75 \\
ADH & ILC & 1 & + & - & - & + & $<5$ \\
ALH & ILC & 1 & + & + & - & - & $<5$ \\
RS & ILC & 1 & + & - & - & + & 5 \\
\hline
\end{tabular}

Abbreviations: ADH, atypical ductal hyperplasia; ALH, atypical lobular hyperplasia; CNB, core needle biopsy; ER, estrogen receptor; FEA, flat epithelial atypia; FISH, fluorescent in situ hybridization; HER2, human epidermal growth factor receptor 2 protein; IDC, invasive ductal carcinoma; ILC, invasive lobular carcinoma; LCIS, lobular carcinoma in situ; PR, progesterone receptor; RS, radial scar; - , negative; +, positive.

cases that were not excised, 7 (39\%) were lost to follow-up, while $11(61 \%)$ were not excised including 10 cases with imaging follow-up and 1 case not excised due to patient input. Of eight lobular carcinoma in situ cases that were not excised, 6 $(75 \%)$ were lost to follow-up, while $2(25 \%)$ were not excised, but had imaging follow-up. Finally, of 29 radial scar cases that did not undergo excision, $12(41 \%)$ were lost to follow-up, while 17 (58\%) had documentation of recommendation for imaging surveillance (specifically 6-month follow-up) after radiology-pathology consensus conference.

Univariate analysis was performed overall and by entity to assess for differences between the lost to follow-up and no excision groups and yielded no significant differences in patient age and radiographic features, including needle gauge, BI-RADS score, calcification vs mass targeting and lesion size; however, our analysis is limited by low case numbers.

Of 333 excision cases, the diagnosis was benign in $98(29 \%)$, residual high risk in 179 (54\%), and upgraded to carcinoma in $56(17 \%)$ (Table 1). Upgraded cases included 42 ductal carcinoma in situ, 9 invasive ductal carcinoma, 3 invasive lobular carcinoma, 1 pleomorphic lobular carcinoma in situ, and 1 isolated tumor cells. Most invasive tumors had low to intermediate modified Bloom and Richardson grade and scores, estrogen receptor (ER) positive, progesterone receptor (PR) positive, and human epidermal growth factor receptor 2 (HER2) protein negative by immunohistochemistry and/or fluorescent in situ hybridization with low proliferation indices (Table 2). By entity, the upgrade rate was $18 \%(35 / 192)$ for atypical ductal hyperplasia, $11 \%$ (6/55) for flat epithelial atypia, 9\% (3/32) for atypical lobular hyperplasia, $28 \%$ (8/29) for lobular carcinoma in situ, and $16 \%(4 / 25)$ for radial scar. 
Table 3 Comparison of cases based on excision status and excision diagnosis

\begin{tabular}{|c|c|c|c|c|c|c|c|c|c|}
\hline & $\begin{array}{c}\text { Excision, } \\
\mathrm{n}=333, \mathrm{n}(\%)\end{array}$ & $\begin{array}{c}\text { No excision, } \\
\mathrm{n}=129, \mathrm{n}(\%)\end{array}$ & P-value & $\begin{array}{c}\text { Upgrade, } \\
\mathrm{n}=56, \mathrm{n}(\%)\end{array}$ & $\begin{array}{c}\text { No upgrade, } \\
\mathrm{n}=277, \mathrm{n}(\%)\end{array}$ & P-value & $\begin{array}{c}\text { Benign, } \mathrm{n}=98 \\
\mathrm{n}(\%)\end{array}$ & $\begin{array}{c}\text { Not benign, } \\
\mathrm{n}=235, \mathrm{n}(\%)\end{array}$ & P-value \\
\hline \multicolumn{10}{|l|}{$C N B d x$} \\
\hline $\mathrm{ADH}$ & $192(58 \%)$ & $57(44 \%)$ & $<0.001^{\mathrm{a}}$ & $35(63 \%)$ & $157(56 \%)$ & 0.242 & $51(52 \%)$ & $141(60 \%)$ & $<0.001^{\mathrm{a}}$ \\
\hline ALH & $32(10 \%)$ & $18(14 \%)$ & & $3(4 \%)$ & 29 (11\%) & & 7 (7\%) & $25(11 \%)$ & \\
\hline FEA & $55(17 \%)$ & $17(13 \%)$ & & $6(11 \%)$ & $49(18 \%)$ & & $20(20 \%)$ & $35(15 \%)$ & \\
\hline LCIS & $29(9 \%)$ & $8(6 \%)$ & & $8(14 \%)$ & $21(8 \%)$ & & $4(4 \%)$ & $25(11 \%)$ & \\
\hline RS & $25(8 \%)$ & $29(22 \%)$ & & $4(7 \%)$ & $21(8 \%)$ & & $16(16 \%)$ & $9(4 \%)$ & \\
\hline Age (years) & & & 0.140 & & & & & & \\
\hline$<50$ & $142(43 \%)$ & $45(35 \%)$ & & $26(46 \%)$ & $116(42 \%)$ & 0.464 & $42(43 \%)$ & $100(43 \%)$ & 0.904 \\
\hline$\geq 50$ & $191(57 \%)$ & $84(65 \%)$ & & $30(54 \%)$ & $161(58 \%)$ & & $56(57 \%)$ & $135(58 \%)$ & \\
\hline$B I-R A D S$ & & & 0.219 & & & & & & \\
\hline$<4 \mathrm{~B}$ & 130 (39\%) & $61(47 \%)$ & & $21(38 \%)$ & 109 (39\%) & 0.908 & $44(45 \%)$ & $86(58 \%)$ & 0.120 \\
\hline$\geq 4 \mathrm{~B}$ & $190(57 \%)$ & $62(48 \%)$ & & $33(59 \%)$ & $156(57 \%)$ & & $53(54 \%)$ & $136(58 \%)$ & \\
\hline Calc targeting & & & 0.072 & & & & & & \\
\hline No & $75(23 \%)$ & $40(31 \%)$ & & $16(29 \%)$ & $59(21 \%)$ & 0.297 & $29(30 \%)$ & $46(20 \%)$ & 0.062 \\
\hline Yes & $258(77 \%)$ & $89(69 \%)$ & & $40(71 \%)$ & $218(79 \%)$ & & $69(70 \%)$ & $189(80 \%)$ & \\
\hline Residual calc & & & 0.122 & & & & & & \\
\hline No & $52(20 \%)$ & $13(15 \%)$ & & $5(13 \%)$ & $46(21 \%)$ & 0.284 & $9(13 \%)$ & $42(22 \%)$ & $0.013^{\mathrm{b}}$ \\
\hline Yes & $64(25 \%)$ & $22(25 \%)$ & & $15(38 \%)$ & $49(22 \%)$ & & $12(17 \%)$ & $52(27 \%)$ & \\
\hline Mass targeting & & & 0.106 & & & & & & \\
\hline No & $266(80 \%)$ & $94(73 \%)$ & & 43 (77\%) & 223 (80\%) & 0.588 & 75 (77\%) & 191 (81\%) & 0.372 \\
\hline Yes & $67(20 \%)$ & $35(25 \%)$ & & $13(23 \%)$ & $54(20 \%)$ & & $23(24 \%)$ & $44(19 \%)$ & \\
\hline Mass size $(\mathrm{cm})$ & & & 0.274 & & & & & & \\
\hline$<1$ & $41(61 \%)$ & $23(65 \%)$ & & $6(46 \%)$ & $35(67 \%)$ & 0.359 & $19(82 \%)$ & $22(50 \%)$ & $0.001^{\mathrm{b}}$ \\
\hline$\geq 1$ & $26(55 \%)$ & $12(34 \%)$ & & $7(54 \%)$ & $19(35 \%)$ & & $4(17 \%)$ & $22(50 \%)$ & \\
\hline Needle gauge & & & 0.685 & & & & & & \\
\hline $9 \mathrm{G}$ & $275(83 \%)$ & $104(81 \%)$ & & $46(82 \%)$ & 229 (83\%) & 1.000 & $81(83 \%)$ & 194 (83\%) & 1.000 \\
\hline $11 \mathrm{G}-14 \mathrm{G}$ & $58(17 \%)$ & $25(19 \%)$ & & $10(18 \%)$ & $48(17 \%)$ & & $17(17 \%)$ & $41(18 \%)$ & \\
\hline
\end{tabular}

Abbreviations: ADH, atypical ductal hyperplasia; ALH, atypical ductal hyperplasia; BI-RADS, Breast Imaging Reporting and Data System score; Calc, calcifications; CNB, core needle biopsy; dx, diagnosis; FEA, flat epithelial atypia; LCIS, lobular carcinoma in situ; RS, radial scar.

Note: Percentage sums may not equal $100 \%$ due to incompletely available data. Mass size and residual calcification reported as percent of total cases with mass and calcification targeting, respectively.

${ }^{\mathrm{a}}$ Compared to $\mathrm{ADH}$, lesions diagnosed as RS on CNB were less likely to be excised (OR $\left.=0.26, P<0.0001, \mathrm{CI}=0.14-0.47\right)$ and less likely to high risk or carcinoma on excision $(\mathrm{OR}=0.29, P=0.014, \mathrm{CI}=0.11-0.77)$ on multivariate logistic regression analysis.

${ }^{\mathrm{b}}$ On post hoc subgroup analysis, ADH seen in CNB cases targeting smaller masses $(<1 \mathrm{~cm})$ were more likely to be benign (vs not benign) (80\% vs $42 \%, P=0.025)$. No other differences within other CNB entity subgroups were significant.

Univariate analysis was utilized to elaborate on differences in age and radiological features based on excision status (excision vs no excision) for the 462 high-risk lesion cases, and excision diagnosis (upgrade vs no upgrade, and benign vs not benign) for the 333 cases that went to excision (Table 3).

Core needle biopsy diagnosis was the only significantly different variable between patients who received excision and patients with no excision $(P<0.001)$ (Table 3, left). On multivariable logistic regression analysis, compared with atypical ductal hyperplasia, lesions diagnosed as radial scar on core needle biopsy were less likely to be excised $(\mathrm{OR}=0.26, \quad P<0.0001, \quad \mathrm{CI}=0.14-0.47) . \quad$ A trend towards younger patients ( $<50$ years old) with more concerning imaging (BI-RADS score $\geq 4 \mathrm{~B}$ ) and targeting of calcifications or larger masses $(\geq 1 \mathrm{~cm})$, with residual calcifications after biopsy was noted among cases that went to excision. However, patient age, BI-RADS score, calcification targeting, mass targeting, and needle gauge were not statistically significant predictors of surgical management (excision vs no excision). Variables with excessive missing values (calcification span, residual calcification on mammogram post-core needle biopsy, and mass size) were excluded from regression models.

Comparing upgrade vs no upgrade (high-risk or benign) groups yielded no significantly different variables (Table 3, middle). A trend towards larger mass size $(\geq 1 \mathrm{~cm})$ and presence of residual calcification was appreciated among upgraded cases. BI-RADS scores and patient age were similar between the upgrade and no upgrade groups.

The data were reorganized to evaluate differences between benign vs not benign (high risk or upgrade) groups (Table 3 , right). Based on logistic regression 
Table 4 Incidental lobular neoplasia is less likely to upgrade on excision

\begin{tabular}{lccr}
\hline & Incidental (n=38) & Targeted (n=23) & P-value \\
\hline Upgrade & $2(5 \%)$ & $9(39 \%)$ & 0.002 \\
No upgrade & $36(95 \%)$ & $14(60 \%)$ & \\
\hline
\end{tabular}

modeling, radial scar was less likely (vs atypical ductal hyperplasia) to be high risk or carcinoma on excision (OR $=0.29, P=0.014, \mathrm{CI}=0.11-0.77)$. Cases that were not benign on excision (vs benign) were more likely to have residual calcifications $(27 \%$ vs $17 \%, P=0.013$ ), and mass size greater than $1 \mathrm{~cm}$ (50\% vs $17 \%, P=0.001)$. On post hoc subgroup analysis, atypical ductal hyperplasia cases that were high risk or upgrade (vs benign) on excision were more likely to have larger masses $(\geq 1 \mathrm{~cm})(P=0.025)$. No other significant difference was found between benign and not benign groups within the separate atypical ductal hyperplasia, flat epithelial atypia, atypical lobular hyperplasia, lobular carcinoma in situ, or radial scar subgroups on post hoc subgroup analysis. However, among cases that were benign on excision, there was a trend towards lower BI-RADS scores $(<4 \mathrm{~B})$, smaller mass sizes $(<1 \mathrm{~cm})$, and no targeting of calcifications or residual calcifications.

Of note, the upgrade rate was highest for lobular carcinoma in situ $(28 \%)$, but this rate decreased to $7 \%(1 / 14)$ for incidental lobular carcinoma in situ, and lobular neoplasia (lobular carcinoma in situ or atypical lobular hyperplasia) diagnosed incidentally (vs targeted) on core needle biopsy was significantly less likely to upgrade on excision $(5 \%$ vs $39 \%$, $P=0.002$ ) (Table 4).

\section{Discussion}

Optimal management for high-risk breast lesions diagnosed on core needle biopsy remains controversial. Institutional differences in excision rates underscore the lack of consensus. ${ }^{22-24}$ The wide range of published upgrade rates to ductal carcinoma in situ and/or invasive mammary carcinoma on excision partly contributes to the problem. Here we present the most comprehensive literature review of reported upgrade rates for atypical ductal hyperplasia, atypical lobular hyperplasia, lobular carcinoma in situ, flat epithelial atypia, and radial scar, along with a summary of the key findings from our statistical analysis with management recommendations (Tables 5-8).

The estimated rate of atypical ductal hyperplasia diagnosis on core needle biopsy has been reported at $3 \%$, and atypical ductal hyperplasia was diagnosed in $4.3 \%$ of core needle biopsy cases at our institution. ${ }^{25}$ On literature review, $23 \%$ of atypical ductal hyperplasia cases were upgraded on average, with a range of $0-62 \%$ (Table 5). ${ }^{12,13,17,19,22,24,26-60}$ In our study, the upgrade rate for patients with atypical ductal hyperplasia diagnosis on core needle biopsy was $18 \%$. No significant decrease in frequency of upgrade for atypical ductal hyperplasia was seen when a larger needle was used for biopsy. Consistent with published findings, atypical ductal hyperplasia lesions associated with a smaller targeted mass $(<1 \mathrm{~cm})$ in our study were statistically more likely to be benign on excision. ${ }^{34}$ However, $17 \%(4 / 23)$ of atypical ductal hyperplasia core needle biopsy cases involving targeting of smaller masses $(<1 \mathrm{~cm})$ still upgraded to carcinoma. In agreement with generally accepted practice guidelines, we conclude that atypical ductal hyperplasia seen on core needle biopsy merits surgical excision.

The estimated rates of lobular neoplasia diagnosis on core needle biopsy have been reported at approximately $1 \% .{ }^{25}$ Our institutional diagnosis rate was $0.9 \%$ for atypical lobular hyperplasia and $0.6 \%$ for lobular carcinoma in situ. Literature review yielded a $9 \%$ mean upgrade rate for atypical lobular hyperplasia (range 0-67\%), and an 18\% mean upgrade rate for lobular carcinoma in situ (range 0-60\%) (Table 6). ${ }^{13,14,18,19,21,28,61-83}$ At our institution, the upgrade rate for atypical lobular hyperplasia was $9 \%$, and the upgrade rate for lobular carcinoma in situ was $24 \%$. Recent studies examining incidentally diagnosed lobular neoplasia reported rates below $2 \% .^{78,82}$ In agreement with these findings, radiology-pathology correlation analysis of our excised lobular neoplasia cases revealed that incidental atypical lobular hyperplasia and lobular carcinoma in situ had an upgrade rate of $5 \%$, significantly lower than the $39 \%$ upgrade rate for targeted lobular neoplasia $(P=0.002)$. Larger needle size in the setting of lobular neoplasia did not decrease upgrade frequency. Similar to the National Comprehensive Cancer Network 2015 Guidelines, we support surgical excision when atypical lobular hyperplasia and lobular carcinoma in situ are diagnosed on core needle biopsy. ${ }^{84}$

In our study, the rate of pure flat epithelial atypia diagnosis on core needle biopsy was $1.3 \%$ with an upgrade rate of $11 \%$. On literature review, approximately $8 \%$ of pure flat epithelial atypia diagnosed on core needle biopsy was upgraded to carcinoma, with a range of $0-21 \%$ (Table 7). ${ }^{19,20,22,24,30,85-104}$ In our study, no statistically significant radiologic differences were seen between upgraded and not upgraded flat epithelial atypia core needle biopsy groups; however, residual calcification after biopsy was associated with upgrade. For pure flat epithelial atypia, as stated in the World Health Organization Working Group, careful radiological-pathological correlation is necessary, and in the absence of residual calcifications or other indications for excision, surveillance may be acceptable. ${ }^{105}$

The estimated rate of radial scar diagnosis on core needle biopsy has been reported at $1-2 \%$, and our rate was $0.9 \% .{ }^{25}$ On literature review, a $7 \%$ average 
Table 5 Literature review of upgrade rates of ADH diagnosed on CNB

\begin{tabular}{|c|c|c|c|c|c|}
\hline & Upgrade rate (\%) & Excision (n) & Upgrade (n) & $D C I S(\mathrm{n})$ & $I M C(\mathrm{n})$ \\
\hline Menes et al & 18 & 685 & 123 & 101 & 22 \\
\hline Bianchi et al & 27 & 275 & 75 & NR & NR \\
\hline Saladin et al & 26 & 266 & 69 & NR & NR \\
\hline Rakha et al & 51 & 261 & 133 & 95 & 38 \\
\hline Khoury et al & 28 & 203 & 57 & 47 & 10 \\
\hline Wagoner et al & 18 & 123 & 22 & 22 & 0 \\
\hline Nguyen et al & 13 & 121 & 16 & 14 & 2 \\
\hline Forgeard et al & 25 & 116 & 29 & 26 & 3 \\
\hline McGhan et al & 18 & 114 & 20 & 15 & 5 \\
\hline Eby et al & 17 & 105 & 18 & 14 & 4 \\
\hline Kohr et al & 20 & 101 & 20 & 17 & 3 \\
\hline McLaughlin et al & 13 & 101 & 13 & 11 & 2 \\
\hline Khoury et al & 15 & 100 & 15 & 12 & 3 \\
\hline Bonnett et al & 9 & 90 & 8 & NR & NR \\
\hline Darling et al & 19 & 86 & 16 & 11 & 5 \\
\hline Sohn et al & 18 & 78 & 14 & 9 & 5 \\
\hline Ko et al & 46 & 74 & 34 & 23 & 11 \\
\hline Lourenco et al & 29 & 73 & 21 & 18 & 3 \\
\hline Allison et al & 11 & 72 & 8 & 5 & 3 \\
\hline Winchester et al & 17 & 65 & 11 & 6 & 5 \\
\hline Andrales et al & 15 & 62 & 9 & 7 & 2 \\
\hline Teng-Swan et al & 23 & 61 & 14 & 14 & 0 \\
\hline Doren et al & 33 & 51 & 17 & 9 & 8 \\
\hline Ely et al & 36 & 47 & 17 & 15 & 2 \\
\hline Burak et al & 13 & 46 & 6 & 2 & 4 \\
\hline Mesurolle et al & 62 & 45 & 28 & 13 & 15 \\
\hline Arpino et al & 29 & 45 & 13 & 11 & 2 \\
\hline Chae et al & 22 & 45 & 10 & 8 & 2 \\
\hline Sneige et al & 7 & 42 & 3 & 3 & 0 \\
\hline Lee et al & 32 & 41 & 13 & 7 & 6 \\
\hline Liberman et al & 54 & 37 & 20 & 13 & 7 \\
\hline Plantade et al & 27 & 37 & 10 & 7 & 3 \\
\hline Pandelidis et al & 14 & 37 & 5 & 4 & 1 \\
\hline Yeh et al & 8 & 36 & 3 & NR & NR \\
\hline Maganini et al & 13 & 32 & 4 & 3 & 4 \\
\hline Travade et al & 19 & 31 & 6 & NR & NR \\
\hline Philpotts et al & 23 & 26 & 6 & 5 & 1 \\
\hline Lourenco et al & 32 & 19 & 6 & 4 & 2 \\
\hline Bedei et al & 12 & 17 & 2 & 2 & 0 \\
\hline Brem et al & 25 & 16 & 4 & 2 & 2 \\
\hline Burbank et al & 0 & 8 & 0 & 0 & 0 \\
\hline Our data & 18 & 192 & 35 & 29 & 6 \\
\hline Mean & 23 & & & & \\
\hline
\end{tabular}

Abbreviations: ADH, atypical ductal hyperplasia; CNB, core needle biopsy; DCIS, ductal carcinoma in situ; IMC, invasive mammary carcinoma; NR, not reported.

upgrade rate was reported with a range of $0-16 \%$ when radial scar was diagnosed on core needle biopsy (Table 8). ${ }^{2,3,15,16,19,23,24,44,106-118}$ Our institutional upgrade rate of $16 \%$ was higher than the reported average, likely due to our small case volume $(n=25)$. No statistically significant radiologic differences were seen between upgraded and not upgraded radial scar core needle biopsy groups in our study. Previous research has shown that incidental and small radial scar lesions $(<5 \mathrm{~mm})$ were less likely to be upgraded on excision. ${ }^{16,110,115}$ There is no consensus for the management of radial scar without atypia. It may be prudent to recommend conservative excision for radial scar without atypia with radial scar size greater $>5 \mathrm{~mm}$. After careful radiological-pathological correlation, watchful surveillance may be acceptable for incidental and small radial scar seen on core needle biopsy. Radial scar with atypia should be excised.

With the exception of mass size $\geq 1 \mathrm{~cm}$ for atypical ductal hyperplasia, no other variables, including BI-RADS score, target lesion (mass vs calcification), mass size, calcification span, needle gauge, or residual calcification seen on mammogram postcore needle biopsy were predictive of upgrade to carcinoma excision for any other entity in our study. However, our analysis carries biases inherent to retrospective reviews, including insufficient case numbers to power statistical regression analysis, and incompletely available data. Heterogeneity in study design, including variations in size, inclusion and exclusion criteria, imaging modality, biopsy 
Table 6 Literature review of upgrade rates of lobular neoplasia diagnosed on CNB

\begin{tabular}{|c|c|c|c|c|c|c|c|c|c|c|c|}
\hline \multicolumn{6}{|c|}{$A L H$} & \multicolumn{6}{|c|}{ LCIS } \\
\hline & Upgrade rate (\%) & Excision (n) & Upgrade (n) & $D C I S(\mathrm{n})$ & $I M C(\mathrm{n})$ & & Upgrade rate (\%) & Excision (n) & Upgrade (n) & $D C I S(\mathrm{n})$ & $I M C(\mathrm{n})$ \\
\hline Zhao et al & 3 & 163 & 5 & 4 & 1 & Neill et al & 4 & 104 & 4 & 1 & 4 \\
\hline Brem et al & 22 & 97 & 21 & 15 & 6 & Zhao et al & 8 & 74 & 6 & 3 & 3 \\
\hline Shah-Khan et al & 1 & 81 & 1 & 1 & 0 & Brem et al & 25 & 67 & 17 & 7 & 10 \\
\hline Subhawong et al & 0 & 56 & 0 & 0 & 0 & Destounis et al & 33 & 63 & 21 & 14 & 7 \\
\hline Karabakhtsian et al & 10 & 52 & 5 & 3 & 2 & D'Alfonoso et al & 8 & 61 & 5 & 1 & 4 \\
\hline Hwang et al & 2 & 48 & 1 & 1 & 0 & Renshaw et al & 4 & 52 & 2 & 1 & 1 \\
\hline Rendi et al & 4 & 48 & 2 & NR & NR & Gao et al & 16 & 49 & 8 & 4 & 4 \\
\hline Renshaw et al & 3 & 40 & 1 & 0 & 1 & Ibrahim et al & 39 & 49 & 19 & 8 & 11 \\
\hline Ibrahim et al & 28 & 40 & 11 & 7 & 4 & Hwang et al & 15 & 39 & 6 & 2 & 4 \\
\hline Rakha et al & 24 & 33 & 8 & 3 & 5 & Heller et al & 27 & 30 & 8 & 4 & 4 \\
\hline Neill et al & 9 & 22 & 2 & 2 & 0 & Karabakhtsian et al & 20 & 25 & 5 & 2 & 3 \\
\hline Foster et al & 10 & 20 & 2 & 2 & 0 & Cangiarrella et al & 10 & 20 & 2 & 1 & 1 \\
\hline Elsheikh et al & 25 & 20 & 5 & 4 & 1 & Londero et al & 60 & 20 & 12 & 5 & 7 \\
\hline Sohn et al & 0 & 19 & 0 & 0 & 0 & Rakha et al & 15 & 20 & 3 & 1 & 2 \\
\hline Cangiarrella et al & 6 & 18 & 1 & 0 & 1 & Rendi et al & 5 & 20 & 1 & NR & NR \\
\hline Arpino et al & 6 & 17 & 1 & 1 & 0 & Shah-Khan et al & 5 & 20 & 1 & 0 & 1 \\
\hline Allen et al & 19 & 16 & 3 & 0 & 3 & Khoury et al & 29 & 17 & 5 & 1 & 4 \\
\hline Mahoney et al & 7 & 15 & 1 & 0 & 1 & Foster et al & 27 & 15 & 4 & 2 & 2 \\
\hline Heller et al & 13 & 15 & 2 & 0 & 2 & O'Neil et al & 29 & 14 & 4 & 1 & 3 \\
\hline O’Neil et al & 8 & 13 & 1 & 0 & 1 & Crisi et al & 15 & 13 & 2 & 0 & 2 \\
\hline Khoury et al & 25 & 12 & 3 & 2 & 1 & Subhawong et al & 33 & 12 & 4 & 1 & 3 \\
\hline Londero et al & 13 & 8 & 1 & 1 & 0 & Elsheikh et al & 27 & 11 & 3 & 0 & 3 \\
\hline Middleton et al & 67 & 6 & 4 & 0 & 4 & Mahoney et al & 40 & 10 & 4 & 2 & 2 \\
\hline Shin et al & 0 & 5 & 0 & 0 & 0 & Middleton et al & 22 & 9 & 2 & 0 & 2 \\
\hline Crisi et al & 0 & 3 & 0 & 0 & 0 & Shin et al & 13 & 8 & 1 & 1 & 1 \\
\hline \multirow{4}{*}{ Our data } & 9 & 32 & 3 & 2 & 1 & Liberman et al & 0 & 5 & 0 & 0 & 0 \\
\hline & & & & & & Arpino et al & 50 & 4 & 2 & 0 & 2 \\
\hline & & & & & & Sohn et al & 0 & 2 & 0 & 0 & 0 \\
\hline & & & & & & Our data & 24 & 29 & 7 & 5 & 2 \\
\hline Mean & 9 & & & & & Mean & 18 & & & & \\
\hline
\end{tabular}

Abbreviations: ALH, lobular carcinoma in situ; CNB, core needle biopsy; DCIS, ductal carcinoma in situ; IMC, invasive mammary carcinoma; LCIS, lobular carcinoma in situ; NR, not reported. 
Table 7 Literature review of upgrade rates of FEA diagnosed on CNB

\begin{tabular}{|c|c|c|c|c|c|}
\hline & Upgrade rate (\%) & Excision (n) & Upgrade (n) & $D C I S(\mathrm{n})$ & $I M C(\mathrm{n})$ \\
\hline Becker et al & 4 & 239 & 10 & 8 & 2 \\
\hline Bianchi et al & 9 & 190 & 18 & NR & NR \\
\hline Villa et al & 6 & 121 & 7 & NR & NR \\
\hline Ozoaru et al & 3 & 95 & 3 & 1 & 2 \\
\hline Peres et al & 10 & 94 & 9 & 5 & 4 \\
\hline Khoumais et al & 11 & 94 & 10 & 5 & 5 \\
\hline Saladin et al & 18 & 82 & 15 & NR & NR \\
\hline Calhoun et al & 7 & 73 & 5 & 3 & 2 \\
\hline Lavoué et al & 13 & 60 & 8 & 6 & 2 \\
\hline Ceugnart et al & 6 & 52 & 3 & 3 & 0 \\
\hline Biggar et al & 6 & 51 & 3 & 2 & 1 \\
\hline David et al & 18 & 40 & 7 & 3 & 4 \\
\hline Senetta et al & 0 & 36 & 0 & 0 & 0 \\
\hline Chivukula et al & 14 & 35 & 5 & 3 & 2 \\
\hline Noske et al & 7 & 30 & 2 & 2 & 0 \\
\hline Dailani et al & 3 & 29 & 1 & 1 & 0 \\
\hline Solorzano et al & 14 & 28 & 4 & 3 & 1 \\
\hline Rakha et al & 21 & 24 & 5 & 4 & 1 \\
\hline Prowler et al & 0 & 24 & 0 & 0 & 0 \\
\hline Piubello et al & 0 & 20 & 0 & 0 & 0 \\
\hline Menes et al & 0 & 16 & 0 & 0 & 0 \\
\hline Ingegnoli et al & 20 & 15 & 3 & 3 & 2 \\
\hline Kunju et al & 21 & 14 & 3 & NR & NR \\
\hline Lee et al & 14 & 7 & 1 & 1 & 0 \\
\hline Martel et al & 0 & 5 & 0 & 0 & 0 \\
\hline Our data & 11 & 55 & 6 & 3 & 3 \\
\hline Mean & 8 & & & & \\
\hline
\end{tabular}

Abbreviations: CNB, core needle biopsy; DCIS, ductal carcinoma in situ; FEA, flat epithelial atypia; IMC, invasive mammary carcinoma; NR, not reported.

Table 8 Literature review of upgrade rates of radial scar without atypia diagnosed on CNB

\begin{tabular}{|c|c|c|c|c|c|}
\hline & Upgrade rate (\%) & Excision (n) & Upgrade (n) & $D C I S(\mathrm{n})$ & $I M C(\mathrm{n})$ \\
\hline Rakha et al & 9 & 278 & 25 & 14 & 11 \\
\hline El-Sayed et al & 12 & 156 & 19 & 10 & 9 \\
\hline Miller et al & 2 & 102 & 2 & 1 & 1 \\
\hline Matrai et al & 0 & 77 & 0 & 0 & 0 \\
\hline Brenner et al & 7 & 73 & 5 & 3 & 2 \\
\hline Andacoglu et al & 6 & 67 & 4 & NR & NR \\
\hline Linda et al & 8 & 62 & 5 & 3 & 2 \\
\hline Bianchi et al & 8 & 49 & 4 & 3 & 1 \\
\hline Conlon et al & 2 & 48 & 1 & 1 & 0 \\
\hline Lieske et al & 9 & 43 & 4 & NR & NR \\
\hline Hayes et al & 10 & 42 & 4 & 4 & 0 \\
\hline Dillon et al & 5 & 41 & 2 & 2 & 0 \\
\hline Rakha et al & 3 & 39 & 1 & 1 & 0 \\
\hline López-Medina et al & 16 & 38 & 6 & 1 & 5 \\
\hline Kirwan et al & 0 & 34 & 0 & 0 & 0 \\
\hline Cawson et al & 0 & 27 & 0 & 0 & 0 \\
\hline Lee et al & 4 & 23 & 1 & 1 & 0 \\
\hline Rajan et al & 5 & 22 & 1 & 1 & 0 \\
\hline Saladin et al & 11 & 18 & 2 & NR & NR \\
\hline Resetkova et al & 0 & 10 & 0 & 0 & 0 \\
\hline Philpotts et al & 0 & 6 & 0 & 0 & 0 \\
\hline Our data & 16 & 25 & 4 & 3 & 1 \\
\hline Mean & 7 & & & & \\
\hline
\end{tabular}

Abbreviations: DCIS, ductal carcinoma in situ; CNB, core needle biopsy; IMC, invasive mammary carcinoma; NR, not reported.

technology, outcome metrics and inclusion of other histopathology in the samples studied, precluded combination of the studies collected into an effective meta-analysis.
This is the largest single-institution analysis of a variety of high-risk breast lesions diagnosed on core needle biopsy, including management recommendations for atypical ductal hyperplasia, flat epithelial 
atypia, atypical lobular hyperplasia, lobular carcinoma in situ, and radial scar. For years teams have published upgrade analyses of high-risk breast lesions diagnosed on core needle biopsy in an effort to prevent over- or undertreatment, and management remains problematic. We agree with the general opinion in the literature that a multicenter controlled study evaluating high-risk breast lesions is needed. ${ }^{25,119-121}$ Research in molecular differences between groups of high-risk lesions may offer further risk stratification. Because ductal carcinoma in situ is being considered for a 'downgrade' to the diagnosis 'borderline breast lesion' with approved trials randomizing patients to active monitoring and standard treatment, similar studies could be performed with high-risk breast lesions such as atypical ductal hyperplasia and lobular carcinoma in situ. ${ }^{122}$ Long-term studies will be important to better characterize the risks and benefits of excision.

\section{Acknowledgments}

We thank UCLA fourth-year medical student Winward Choy for assistance with the statistical analyses.

\section{Disclosure/conflict of interest}

The authors declare no conflict of interest.

\section{References}

1 Andreu FJ, Saez A, Sentis M, et al. Breast core biopsy reporting categories-an internal validation in a series of 3054 consecutive lesions. Breast 2007;16:94-101.

2 Dillon MF, McDermott EW, Hill AD, et al. Predictive value of breast lesions of 'uncertain malignant potential' and 'suspicious for malignancy' determined by needle core biopsy. Ann Surg Oncol 2007;14: 704-711.

3 El-Sayed ME, Rakha EA, Reed J, et al. Predictive value of needle core biopsy diagnoses of lesions of uncertain malignant potential (B3) in abnormalities detected by mammographic screening. Histopathology 2008;53:650-657.

4 Houssami N, Ciatto S, Bilous M, et al. Borderline breast core needle histology: predictive values for malignancy in lesions of uncertain malignant potential (B3). Br J Cancer 2007;96:1253-1257.

5 Dupont WD, Page DL. Risk factors for breast cancer in women with proliferative breast disease. N Engl J Med 1985;312:146-151.

6 Jacobs TW, Byrne C, Colditz G, et al. Radial scars in benign breast-biopsy specimens and the risk of breast cancer. N Engl J Med 1999;340:430-436.

7 Sloane JP, Mayers MM. Carcinoma and atypical hyperplasia in radial scars and complex sclerosing lesions: importance of lesion size and patient age. Histopathology 1993;23:225-231.
8 Sinn HP, Helmchen B, Heil J, et al. Lobular neoplasms and invasive lobular breast cancer. Pathologe 2014;35: 45-53.

9 Collins LC, Achacoso NA, Nekhlyudov L, et al. Clinical and pathologic features of ductal carcinoma in situ associated with the presence of flat epithelial atypia: an analysis of 543 patients. Mod Pathol 2007;20:1149-1155.

10 Moinfar F, Man YG, Bratthauer GL, et al. Genetic abnormalities in mammary ductal intraepithelial neoplasia-flat type ('clinging ductal carcinoma in situ'): a simulator of normal mammary epithelium. Cancer 2000;88:2072-2081.

11 Schnitt SJ. The diagnosis and management of preinvasive breast disease: flat epithelial atypia-classification, pathologic features and clinical significance. Breast Cancer Res 2003;5:263-268.

12 Burbank F. Stereotactic breast biopsy of atypical ductal hyperplasia and ductal carcinoma in situ lesions: improved accuracy with directional, vacuumassisted biopsy. Radiology 1997;202:843-847.

13 Liberman L, Dershaw DD, Glassman JR, et al. Analysis of cancers not diagnosed at stereotactic core breast biopsy. Radiology 1997;203:151-157.

14 Londero V, Zuiani C, Linda A, et al. Lobular neoplasia: core needle breast biopsy underestimation of malignancy in relation to radiologic and pathologic features. Breast 2008;17:623-630.

15 Lopez-Medina A, Cintora E, Mugica B, et al. Radial scars diagnosed at stereotactic core-needle biopsy: surgical biopsy findings. Eur Radiol 2006;16: 1803-1810.

16 Matrai C, D'Alfonso TM, Pharmer L, et al. Advocating nonsurgical management of patients with small, incidental radial scars at the time of needle core biopsy: a study of 77 cases. Arch Pathol Lab Med 2015;139:1137-1142.

17 Mesurolle B, Perez JC, Azzumea F, et al. Atypical ductal hyperplasia diagnosed at sonographically guided core needle biopsy: frequency, final surgical outcome, and factors associated with underestimation. AJR Am J Roentgenol 2014;202:1389-1394.

18 Middleton LP, Grant S, Stephens T, et al. Lobular carcinoma in situ diagnosed by core needle biopsy: when should it be excised? Mod Pathol 2003;16: 120-129.

19 Rakha EA, Lee AH, Jenkins JA, et al. Characterization and outcome of breast needle core biopsy diagnoses of lesions of uncertain malignant potential (B3) in abnormalities detected by mammographic screening. Int J Cancer 2011;129:1417-1424.

20 Senetta R, Campanino PP, Mariscotti G, et al. Columnar cell lesions associated with breast calcifications on vacuum-assisted core biopsies: clinical, radiographic, and histological correlations. Mod Pathol 2009;22:762-769.

21 Sohn VY, Arthurs ZM, Kim FS, et al. Lobular neoplasia: is surgical excision warranted? Am Surg 2008;74:172-177.

22 Menes TS, Rosenberg R, Balch S, et al. Upgrade of high-risk breast lesions detected on mammography in the Breast Cancer Surveillance Consortium. Am J Surg 2014;207:24-31.

23 Rakha EA, Ho BC, Naik V, et al. Outcome of breast lesions diagnosed as lesion of uncertain malignant potential (B3) or suspicious of malignancy (B4) on needle core biopsy, including detailed 
review of epithelial atypia. Histopathology 2011;58: 626-632.

24 Saladin C, Haueisen H, Kampmann G, et al. Lesions with unclear malignant potential (B3) after minimally invasive breast biopsy: evaluation of vacuum biopsies performed in Switzerland and recommended further management. Acta Radiol 2015;57:815-821.

25 Calhoun BC, Collins LC. Recommendations for excision following core needle biopsy of the breast: a contemporary evaluation of the literature. Histopathology 2016;68:138-151.

26 Adrales G, Turk $\mathrm{P}$, Wallace $\mathrm{T}$, et al. Is surgical excision necessary for atypical ductal hyperplasia of the breast diagnosed by Mammotome? Am J Surg 2000;180:313-315.

27 Allison KH, Eby PR, Kohr J, et al. Atypical ductal hyperplasia on vacuum-assisted breast biopsy: suspicion for ductal carcinoma in situ can stratify patients at high risk for upgrade. Hum Pathol 2011;42:41-50.

28 Arpino G, Allred DC, Mohsin SK, et al. Lobular neoplasia on core-needle biopsy-clinical significance. Cancer 2004;101:242-250.

29 Bedei L, Falcini F, Sanna PA, et al. Atypical ductal hyperplasia of the breast: the controversial management of a borderline lesion: experience of 47 cases diagnosed at vacuum-assisted biopsy. Breast 2006;15: 196-202.

30 Bianchi S, Bendinelli B, Castellano I, et al. Morphological parameters of flat epithelial atypia (FEA) in stereotactic vacuum-assisted needle core biopsies do not predict the presence of malignancy on subsequent surgical excision. Virchows Arch 2012;461:405-417.

31 Bonnett M, Wallis T, Rossmann M, et al. Histopathologic analysis of atypical lesions in image-guided core breast biopsies. Mod Pathol 2003;16:154-160.

32 Brem RF, Behrndt VS, Sanow L, et al. Atypical ductal hyperplasia: histologic underestimation of carcinoma in tissue harvested from impalpable breast lesions using 11-gauge stereotactically guided directional vacuum-assisted biopsy. AJR Am J Roentgenol 1999;172:1405-1407.

33 Burak WE Jr, Owens KE, Tighe MB, et al. Vacuumassisted stereotactic breast biopsy: histologic underestimation of malignant lesions. Arch Surg 2000;135: 700-703.

34 Chae BJ, Lee A, Song BJ, et al. Predictive factors for breast cancer in patients diagnosed atypical ductal hyperplasia at core needle biopsy. World J Surg Oncol 2009;7:77.

35 Darling ML, Smith DN, Lester SC, et al. Atypical ductal hyperplasia and ductal carcinoma in situ as revealed by large-core needle breast biopsy: results of surgical excision. AJR Am J Roentgenol 2000;175: 1341-1346.

36 Doren E, Hulvat M, Norton J, et al. Predicting cancer on excision of atypical ductal hyperplasia. Am J Surg 2008;195:358-361 discussion 61-2.

37 Eby PR, Ochsner JE, DeMartini WB, et al. Is surgical excision necessary for focal atypical ductal hyperplasia found at stereotactic vacuum-assisted breast biopsy? Ann Surg Oncol 2008;15:3232-3238.

38 Ely KA, Carter BA, Jensen RA, et al. Core biopsy of the breast with atypical ductal hyperplasia: a probabilistic approach to reporting. Am J Surg Pathol 2001;25:1017-1021.

39 Forgeard C, Benchaib M, Guerin N, et al. Is surgical biopsy mandatory in case of atypical ductal hyperplasia on 11-gauge core needle biopsy? A retrospective study of 300 patients. Am J Surg 2008;196:339-345.

40 Khoury $\mathrm{T}$, Chen X, Wang D, et al. Nomogram to predict the likelihood of upgrade of atypical ductal hyperplasia diagnosed on a core needle biopsy in mammographically detected lesions. Histopathology 2015;67:106-120.

41 Khoury T, Li Z, Sanati S, et al. The risk of upgrade for atypical ductal hyperplasia detected on magnetic resonance imaging-guided biopsy: a study of 100 cases from four academic institutions. Histopathology 2016;68:713-721.

42 Ko E, Han W, Lee JW, et al. Scoring system for predicting malignancy in patients diagnosed with atypical ductal hyperplasia at ultrasound-guided core needle biopsy. Breast Cancer Res Treat 2008;112: 189-195.

43 Kohr JR, Eby PR, Allison KH, et al. Risk of upgrade of atypical ductal hyperplasia after stereotactic breast biopsy: effects of number of foci and complete removal of calcifications. Radiology 2010;255:723-730.

44 Lee AH, Denley HE, Pinder SE, et al. Excision biopsy findings of patients with breast needle core biopsies reported as suspicious of malignancy (B4) or lesion of uncertain malignant potential (B3). Histopathology 2003;42:331-336.

45 Lourenco AP, Khalil H, Sanford M, et al. High-risk lesions at MRI-guided breast biopsy: frequency and rate of underestimation. AJR Am J Roentgenol 2014;203:682-686.

46 Lourenco AP, Mainiero MB, Lazarus E, et al. Stereotactic breast biopsy: comparison of histologic underestimation rates with 11- and 9-gauge vacuumassisted breast biopsy. AJR Am J Roentgenol 2007; 189:W275-W279.

47 Maganini RO, Klem DA, Huston BJ, et al. Upgrade rate of core biopsy-determined atypical ductal hyperplasia by open excisional biopsy. Am J Surg 2001;182: 355-358.

48 McGhan LJ, Pockaj BA, Wasif N, et al. Atypical ductal hyperplasia on core biopsy: an automatic trigger for excisional biopsy? Ann Surg Oncol 2012;19: 3264-3269.

49 McLaughlin CT, Neal CH, Helvie MA. Is the upgrade rate of atypical ductal hyperplasia diagnosed by core needle biopsy of calcifications different for digital and film-screen mammography? AJR Am J Roentgenol 2014;203:917-922.

50 Nguyen CV, Albarracin CT, Whitman GJ, et al. Atypical ductal hyperplasia in directional vacuumassisted biopsy of breast microcalcifications: considerations for surgical excision. Ann Surg Oncol 2011;18:752-761.

51 Pandelidis S, Heiland D, Jones D, et al. Accuracy of 11-gauge vacuum-assisted core biopsy of mammographic breast lesions. Ann Surg Oncol 2003;10: 43-47.

52 Philpotts LE, Lee CH, Horvath LJ, et al. Underestimation of breast cancer with II-gauge vacuum suction biopsy. AJR Am J Roentgenol 2000;175:1047-1050.

53 Plantade R, Hammou JC, Fighiera M, et al. Underestimation of breast carcinoma with 11-gauge stereotactically guided directional vacuum-assisted biopsy. J Radiol 2004;85:391-401.

54 Sneige N, Lim SC, Whitman GJ, et al. Atypical ductal hyperplasia diagnosis by directional vacuum-assisted 
stereotactic biopsy of breast microcalcifications. Considerations for surgical excision. Am J Clin Pathol 2003;119:248-253.

55 Sohn V, Arthurs Z, Herbert G, et al. Atypical ductal hyperplasia: improved accuracy with the 11gauge vacuum-assisted versus the 14-gauge core biopsy needle. Ann Surg Oncol 2007;14:2497-2501.

56 Teng-Swan Ho J, Tan PH, Hee SW, et al. Underestimation of malignancy of atypical ductal hyperplasia diagnosed on 11-gauge stereotactically guided Mammotome breast biopsy: an Asian breast screen experience. Breast 2008;17:401-406.

57 Travade A, Isnard A, Bouchet F, et al. Non-palpable breast lesions and core needle biopsy with Mammotome 11G: is surgery required in patients with atypical ductal hyperplasia? J Radiol 2006;87: 307-310.

58 Wagoner MJ, Laronga C, Acs G. Extent and histologic pattern of atypical ductal hyperplasia present on core needle biopsy specimens of the breast can predict ductal carcinoma in situ in subsequent excision. Am J Clin Pathol 2009;131:112-121.

59 Winchester DJ, Bernstein JR, Jeske JM, et al. Upstaging of atypical ductal hyperplasia after vacuum-assisted 11-gauge stereotactic core needle biopsy. Arch Surg 2003;138:619-622; discussion 22-3.

60 Yeh IT, Dimitrov D, Otto P, et al. Pathologic review of atypical hyperplasia identified by image-guided breast needle core biopsy. Correlation with excision specimen. Arch Pathol Lab Med 2003;127:49-54.

61 Allen S, Levine EA, Lesko $\mathrm{N}$, et al. Is excisional biopsy and chemoprevention warranted in patients with atypical lobular hyperplasia on core biopsy? Am Surg 2015;81:876-878.

62 Brem RF, Lechner MC, Jackman RJ, et al. Lobular neoplasia at percutaneous breast biopsy: variables associated with carcinoma at surgical excision. AJR Am J Roentgenol 2008;190:637-641.

63 Cangiarella J, Guth A, Axelrod D, et al. Is surgical excision necessary for the management of atypical lobular hyperplasia and lobular carcinoma in situ diagnosed on core needle biopsy? A report of 38 cases and review of the literature. Arch Pathol Lab Med 2008;132:979-983.

64 Crisi GM, Mandavilli S, Cronin E, et al. Invasive mammary carcinoma after immediate and short-term follow-up for lobular neoplasia on core biopsy. Am J Surg Pathol 2003;27:325-333.

65 D'Alfonso TM, Wang K, Chiu YL, et al. Pathologic upgrade rates on subsequent excision when lobular carcinoma in situ is the primary diagnosis in the needle core biopsy with special attention to the radiographic target. Arch Pathol Lab Med 2013;137: 927-935.

66 Destounis SV, Murphy PF, Seifert PJ, et al. Management of patients diagnosed with lobular carcinoma in situ at needle core biopsy at a community-based outpatient facility. AJR Am J Roentgenol 2012;198: 281-287.

67 Elsheikh TM, Silverman JF. Follow-up surgical excision is indicated when breast core needle biopsies show atypical lobular hyperplasia or lobular carcinoma in situ: a correlative study of 33 patients with review of the literature. Am J Surg Pathol 2005;29: 534-543.

68 Foster MC, Helvie MA, Gregory NE, et al. Lobular carcinoma in situ or atypical lobular hyperplasia at core-needle biopsy: is excisional biopsy necessary? Radiology 2004;231:813-819.

69 Gao F, Carter G, Tseng G, et al. Clinical importance of histologic grading of lobular carcinoma in situ in breast core needle biopsy specimens: current issues and controversies. Am J Clin Pathol 2010;133:767-771.

70 Heller SL, Elias K, Gupta A, et al. Outcome of highrisk lesions at MRI-guided 9-gauge vacuum- assisted breast biopsy. AJR Am J Roentgenol 2014;202: 237-245.

71 Hwang H, Barke LD, Mendelson EB, et al. Atypical lobular hyperplasia and classic lobular carcinoma in situ in core biopsy specimens: routine excision is not necessary. Mod Pathol 2008;21:1208-1216.

72 Ibrahim N, Bessissow A, Lalonde L, et al. Surgical outcome of biopsy-proven lobular neoplasia: is there any difference between lobular carcinoma in situ and atypical lobular hyperplasia? AJR Am J Roentgenol 2012;198:288-291.

73 Karabakhtsian RG, Johnson R, Sumkin J, et al. The clinical significance of lobular neoplasia on breast core biopsy. Am J Surg Pathol 2007;31:717-723.

74 Khoury T, Kumar PR, Li Z, et al. Lobular neoplasia detected in MRI-guided core biopsy carries a high risk for upgrade: a study of 63 cases from four different institutions. Mod Pathol 2016;29:25-33.

75 Mahoney MC, Robinson-Smith TM, Shaughnessy EA. Lobular neoplasia at 11-gauge vacuum-assisted stereotactic biopsy: correlation with surgical excisional biopsy and mammographic follow-up. AJR Am J Roentgenol 2006;187:949-954.

76 Niell B, Specht M, Gerade B, et al. Is excisional biopsy required after a breast core biopsy yields lobular neoplasia? AJR Am J Roentgenol 2012;199: 929-935.

77 O'Neil M, Madan R, Tawfik OW, et al. Lobular carcinoma in situ/atypical lobular hyperplasia on breast needle biopsies: does it warrant surgical excisional biopsy? A study of 27 cases. Ann Diagn Pathol 2010;14:251-255.

78 Rendi MH, Dintzis SM, Lehman CD, et al. Lobular insitu neoplasia on breast core needle biopsy: imaging indication and pathologic extent can identify which patients require excisional biopsy. Ann Surg Oncol 2012;19:914-921.

79 Renshaw AA, Derhagopian RP, Martinez P, et al. Lobular neoplasia in breast core needle biopsy specimens is associated with a low risk of ductal carcinoma in situ or invasive carcinoma on subsequent excision. Am J Clin Pathol 2006;126:310-313.

80 Shah-Khan MG, Geiger XJ, Reynolds C, et al. Longterm follow-up of lobular neoplasia (atypical lobular hyperplasia/lobular carcinoma in situ) diagnosed on core needle biopsy. Ann Surg Oncol 2012;19: 3131-3138.

81 Shin SJ, Rosen PP. Excisional biopsy should be performed if lobular carcinoma in situ is seen on needle core biopsy. Arch Pathol Lab Med 2002;126:697-701.

82 Subhawong AP, Subhawong TK, Khouri N, et al. Incidental minimal atypical lobular hyperplasia on core needle biopsy: correlation with findings on follow-up excision. Am J Surg Pathol 2010;34: 822-828.

83 Zhao C, Desouki MM, Florea A, et al. Pathologic findings of follow-up surgical excision for lobular neoplasia on breast core biopsy performed for calcification. Am J Clin Pathol 2012;138:72-78. 
84 National Comprehensive Cancer Network (NCCN). Cited 28 February 2016. Available at http://www.nccn. org/professionals/physician_gls/f_guidelines.asp.

85 Becker AK, Gordon PB, Harrison DA, et al. Flat ductal intraepithelial neoplasia 1A diagnosed at stereotactic core needle biopsy: is excisional biopsy indicated? AJR Am J Roentgenol 2013;200:682-688.

86 Biggar MA, Kerr KM, Erzetich LM, et al. Columnar cell change with atypia (flat epithelial atypia) on breast core biopsy-outcomes following open excision. Breast J 2012;18:578-581.

87 Calhoun BC, Sobel A, White RL, et al. Management of flat epithelial atypia on breast core biopsy may be individualized based on correlation with imaging studies. Mod Pathol 2015;28:670-676.

88 Ceugnart L, Doualliez V, Chauvet MP, et al. Pure flat epithelial atypia: is there a place for routine surgery? Diagn Interv Imaging 2013;94:861-869.

89 Chivukula M, Bhargava R, Tseng G, et al. Clinicopathologic implications of 'flat epithelial atypia' in core needle biopsy specimens of the breast. Am J Clin Pathol 2009;131:802-808.

90 David N, Labbe-Devilliers C, Moreau D, et al. Diagnosis of flat epithelial atypia (FEA) after stereotactic vacuum-assisted biopsy (VAB) of the breast: what is the best management: systematic surgery for all or follow-up? J Radiol 2006;87:1671-1677.

91 Dialani V, Venkataraman S, Frieling G, et al. Does isolated flat epithelial atypia on vacuum-assisted breast core biopsy require surgical excision? Breast J 2014;20:606-614.

92 Ingegnoli A, d'Aloia C, Frattaruolo A, et al. Flat epithelial atypia and atypical ductal hyperplasia: carcinoma underestimation rate. Breast J 2010;16: 55-59.

93 Khoumais NA, Scaranelo AM, Moshonov H, et al. Incidence of breast cancer in patients with pure flat epithelial atypia diagnosed at core-needle biopsy of the breast. Ann Surg Oncol 2013;20:133-138.

94 Kunju LP, Kleer CG. Significance of flat epithelial atypia on mammotome core needle biopsy: should it be excised? Hum Pathol 2007;38:35-41.

95 Lavoue V, Roger CM, Poilblanc M, et al. Pure flat epithelial atypia (DIN 1a) on core needle biopsy: study of 60 biopsies with follow-up surgical excision. Breast Cancer Res Treat 2011;125:121-126.

96 Lee TY, Macintosh RF, Rayson D, et al. Flat epithelial atypia on breast needle core biopsy: a retrospective study with clinical-pathological correlation. Breast J 2010;16:377-383.

97 Martel M, Barron-Rodriguez P, Tolgay Ocal I, et al. Flat DIN 1 (flat epithelial atypia) on core needle biopsy: 63 cases identified retrospectively among 1,751 core biopsies performed over an 8-year period (1992-1999). Virchows Arch 2007;451:883-891.

98 Noske A, Pahl S, Fallenberg E, et al. Flat epithelial atypia is a common subtype of B3 breast lesions and is associated with noninvasive cancer but not with invasive cancer in final excision histology. Hum Pathol 2010;41:522-527.

99 Peres A, Barranger E, Becette V, et al. Rates of upgrade to malignancy for 271 cases of flat epithelial atypia (FEA) diagnosed by breast core biopsy. Breast Cancer Res Treat 2012;133:659-666.

100 Piubello Q, Parisi A, Eccher A, et al. Flat epithelial atypia on core needle biopsy: which is the right management? Am J Surg Pathol 2009;33:1078-1084.
101 Prowler VL, Joh JE, Acs G, et al. Surgical excision of pure flat epithelial atypia identified on core needle breast biopsy. Breast 2014;23:352-356.

102 Solorzano S, Mesurolle B, Omeroglu A, et al. Flat epithelial atypia of the breast: pathological-radiological correlation. AJR Am J Roentgenol 2011;197:740-746.

103 Uzoaru I, Morgan BR, Liu ZG, et al. Flat epithelial atypia with and without atypical ductal hyperplasia: to re-excise or not. Results of a 5-year prospective study. Virchows Arch 2012;461:419-423.

104 Villa A, Chiesa F, Massa T, et al. Flat epithelial atypia: comparison between 9-gauge and 11-gauge devices. Clin Breast Cancer 2013;13:450-454.

105 Lakhani SR, Ellis IO, Schnitt SJ, et al. (eds). World Health Organization Classification of Tumours of the Breast, 4th edn. International Agency for Research on Cancer (IARC): 2012, pp 87.

106 Andacoglu O, Kanbour-Shakir A, Teh YC, et al. Rationale of excisional biopsy after the diagnosis of benign radial scar on core biopsy: a single institutional outcome analysis. Am J Clin Oncol 2013;36:7-11.

107 Bianchi S, Giannotti E, Vanzi E, et al. Radial scar without associated atypical epithelial proliferation on image-guided 14-gauge needle core biopsy: analysis of 49 cases from a single-centre and review of the literature. Breast 2012;21:159-164.

108 Brenner RJ, Jackman RJ, Parker SH, et al. Percutaneous core needle biopsy of radial scars of the breast: when is excision necessary? AJR Am J Roentgenol 2002;179:1179-1184.

109 Cawson JN, Malara F, Kavanagh A, et al. Fourteengauge needle core biopsy of mammographically evident radial scars: is excision necessary? Cancer 2003;97:345-351.

110 Conlon N, D'Arcy C, Kaplan JB, et al. Radial scar at image-guided needle biopsy: is excision necessary? Am J Surg Pathol 2015;39:779-785.

111 Hayes BD, O'Doherty A, Quinn CM. Correlation of needle core biopsy with excision histology in screen-detected B3 lesions: the Merrion Breast Screening Unit experience. J Clin Pathol 2009;62: 1136-1140.

112 Kirwan SE, Denton ER, Nash RM, et al. Multiple 14G stereotactic core biopsies in the diagnosis of mammographically detected stellate lesions of the breast. Clin Radiol 2000;55:763-766.

113 Lieske B, Ravichandran D, Alvi A, et al. Screendetected breast lesions with an indeterminate (B3) core needle biopsy should be excised. Eur J Surg Oncol 2008;34:1293-1298.

114 Linda A, Zuiani C, Furlan A, et al. Radial scars without atypia diagnosed at imaging-guided needle biopsy: how often is associated malignancy found at subsequent surgical excision, and do mammography and sonography predict which lesions are malignant? AJR Am J Roentgenol 2010;194:1146-1151.

115 Miller CL, West JA, Bettini AC, et al. Surgical excision of radial scars diagnosed by core biopsy may help predict future risk of breast cancer. Breast Cancer Res Treat 2014;145:331-338.

116 Philpotts LE, Shaheen NA, Jain KS, et al. Uncommon high-risk lesions of the breast diagnosed at stereotactic core-needle biopsy: clinical importance. Radiology 2000;216:831-837.

117 Rajan S, Wason AM, Carder PJ. Conservative management of screen-detected radial scars: role of mammotome excision. J Clin Pathol 2011;64:65-68. 
118 Resetkova E, Edelweiss M, Albarracin CT, et al. Management of radial sclerosing lesions of the breast diagnosed using percutaneous vacuum-assisted core needle biopsy: recommendations for excision based on seven years' of experience at a single institution. Breast Cancer Res Treat 2011;127:335-343.

119 Javitt MC. Diagnosis and management of high-risk breast lesions: Aristotle's dilemma. AJR Am J Roentgenol 2012;198:246-248.
120 Masood S, Rosa M. Borderline breast lesions: diagnostic challenges and clinical implications. Adv Anat Pathol 2011;18:190-198.

121 Morrow M, Schnitt SJ, Norton L. Current management of lesions associated with an increased risk of breast cancer. Nat Rev Clin Oncol 2015;12:227-238.

122 Francis A, Fallowfield L, Rea D. The LORIS Trial: addressing overtreatment of ductal carcinoma in situ. Clin Oncol (R Coll Radiol) 2015;27:6-8. 